$$
\text { تطوير مادة القراءة الناقدة على أساس القرآن لطلبة اللغة العربية }
$$

\title{
Critical Reading Material Development based on Quran for Arabic Student
}

\author{
Edy Murdani Zulkifli \\ Mahasiswa Program doktoral Pendidikan Bahasa Arab \\ UIN Maulana Malik Ibrahim Malang \\ edymurdaniz@gmail.com \\ Wildana Wargadinata \\ UIN Maulana Malik Ibrahim Malang \\ wargadi@gmail.com \\ Sutaman \\ UIN Maulana Malik Ibrahim Malang \\ sutaman@vin-malang.ac.id
}

\begin{abstract}
This study aims to develop critical reading skills material based on conversations in the Koran for Arabic Language Students at IAIN Samarinda. The research method used is the research and development of the Balitho and Jolly models with the following stages: (1) identification of the problem as a disclosure of needs; (2) exploration as a needs analysis; (3) realization of context as product design planning; (4) pedagogical realization as product preparation; (5) Product realization as the initial product and validation of the expert team; (6) implementation as a product test in the field in limited groups and large groups; (7) evaluation as a revision for product improvement. The results of the study: (1) the teaching material for critical reading skills based on conversations in the Koran (2) The teaching material has characteristics (a) contains facts and opinions; (b) the material contains many arguments; (c) contains many words which, if expressed correctly, can create new understandings (3) the application of teaching materials to Arabic students shows quite effective results. The new finding of this research is the teaching material which contains various
\end{abstract}


Edy Murdani Zulkifli, Wildana Wargadinata \& Sutaman

facts and opinions, as well as many arguments that can improve students' ability to think critically

Keywords: Conversation in Al Quran, Critical Thinking, Reading Skills

\section{أ- - 2 - أمقدمة}

لقد جرى مفهوم الإسلامي للعقل (الفكر) يشمل البعد الإيماني للمعرفة أيضا

مستنيرة بالقيم الأخلاقية، يحتوي القرآن على كالام الله سبحانه وتعالى ويعمل كهدا ية تفصل بين الصواب والخطأ لمساعدة البشرية في جميع احتياجاتا. من الواضح أن القرآن يجب أن يُفهم على أنه هداية للبشرية في كل العصور(Qadhlawi, 2016). وبالتالي، من الضروري أن نفهم كمسلمين ما يقوله الله ونعكسه بقدر ما نستطيع. بدون فهم محتويات Saadah \& Baharuddin, ) القرآن ، يصعب على المسلم تلقي تعاليمه وتنفيذها في حياتم Nurfarhana 2017 ). للقرآن مفردات واسعة جدًا في تحسين مهارات التفكير والتعبير عن المشاعر وبناء مهارات الجدل وفي النهاية سيكون لها تأثير كبير على الإبداع (Zaid, 2011). تتكون القراءة السائدة للقرآن عن العقلانية من تحالف الإيمان والعقل الذي يدرك أيضًا الجانب الميتافيزيقي للواقع وحدود العقل البشري.

ومن أساليب القرآن أسلوب المحاورة، المحاورة في دلالتها الواقعة وهي محاولة كل من طرف الحديث أوأحدهما أن يقنع الأخر بمنطقه ووجهة رأيه، وإذن فالمحاورة فن أغلب صورها مباراة أومناسفة أدائها للسان. وهي في كل أحوالها تمثل موقف المحاور ورأيه وحججه وفوق ذلك فإنا تمثل شخصيته ومقدار عقل وتفكيره، فأما شخصيته فتبدومن خلال طريقة المحاورة، ومدى حرصه على بلوغ هدفه ومدى مقداره على محاصرة منافسة أوخصمه، وأما عقله وتفكيره فيبدو من خلال حجته التى يسوقها ومن خلال ترتيب أفكاره وتسلسل المقدمات والنتائج فن حديثه ومن الواضح أن القرآن الكريم جعل الإهتمام باللسان والمنطق في المكان البارز المرموق (Abdul halim hifni, 1995). و.ها تعلمنا كيف نجعل مواقفنا امتدادا لها، لأهما تمثل أفضل الأساليب في موقف الصراع الفكرى للرسالة في خط الحياة، محا يدفعنا 
إلى أن نتلمس فيها مواطن القوة، التى تقودنا إلى مواقع الرسالات العملية فن متفرق الطرق (As sayyid muhammad husain fadhlullah, 1396). وقد اشار سلطان العلاقة بين الحوار والفكرى، أن الحوار يفتح المدارك الفكرية ويربط بين الأفهام وتنتج بعد ذلك التوجيهات والإ تناعات، وأن المادة الأساسية للحوار هوالفكر وهودواء لمعالجة الخلل في الأفكار .(Sulton bin musfir as-Shoidi, 1431) يستلزم هذا الدور الإرشادي للعلامات الإلهية طلبًا مصاحبًا يوضع على البشر للانخراط في فهم عقلي للعلامات واستخلاص استنتاجات حول اكتشاف الحقيقة والتوجيه الصحيح (Laleh Bakhtiar, 2017). ما لا شك فيه أن القرآن كمصدر للمعرفة يوفر طريقة تعلم للقراء(Aini \& Ramli, 2018)، من خلال الأوامر والتكرار والأمثال والقصص و و

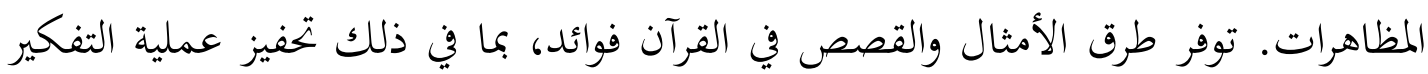
لدى كل شخص حول ما يتم نقله وربطه بما يهدث في حياته (Sarah Risha, 2013). إذا جاز التعبير، هناك خط فاصل بين المفهوم الإسلامي والغربى للعقلانية، خاصة في سياق ما

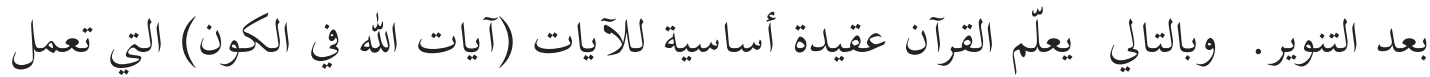
كمؤشرات للغرض الإثباتي على جميع مستويات النشأة. فإن القرآن يجعل مراجع متكررة

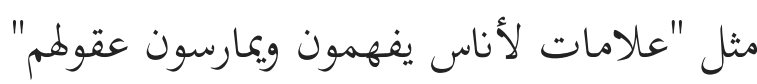

و من هذه المنطلقات، هذه الدراسة تريد أن تبحث (1) تطوير مادة القراءة الناقدة

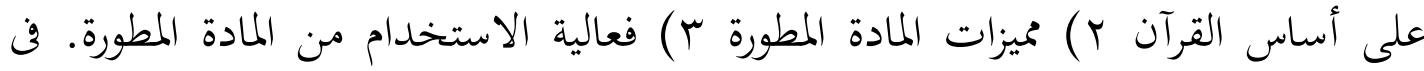
الواقع، أن البحوث المتعلقة بالتفكير الناقد و القرآن فن نفس الموضوع فن بجال التطوير قليل التنفيذ. هناك بحث يشير إلى قبول استخدام القصص فن القرآن في عملية تعلم التفكير

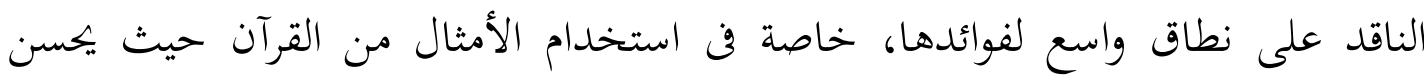
مهارة التفكير الناقد لدى المتعلمين (Akhavanmalayeri \& Faghihi, 2018).

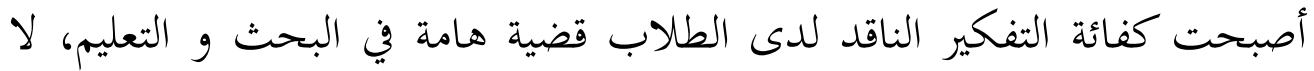
سيما في عصرنا الحاضر حيث يتطور التكنولوجى بشكل كبير، ويؤكد 
و huitt على ذلك ويقولون إن التفكير الناقد عنصر من العناصر المهمة فن تعليم و تعليم

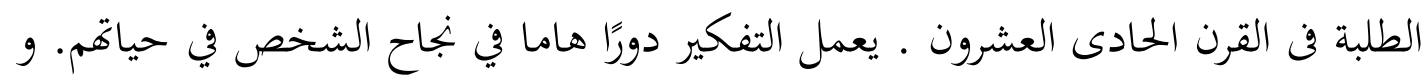
يجب إدخال القراءة النقدية في التعليم الرسمي، خاصة في الجامعات. تسمح مهارات القراءة

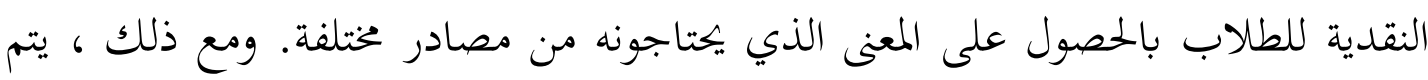
توسيع المعلومات التي يمكن الوصول إليها من خلال قراءة مصادر مختلفة (Arifin, 2020). أضاف ذلك بأن الحركة في عصر الإصلاح قد حولت الأنظار الانتباه إلى التفكير بشكل

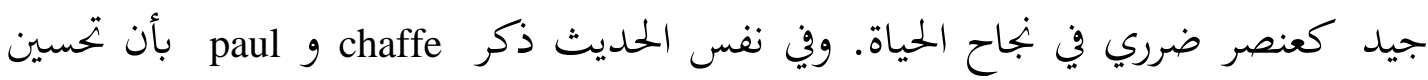
كفائة التفكير الناقد لدى الطلاب هو لب التعليم الهادف (Rezaei et al., 2011) و ذلك تهريك لان عملية التفكير الناقد يميل كثيرا إلى الجودة من قبل الطلبة، لما ترتقى كفائة التعلم و إنما ترتقى قوة التفكير الناقد من قبلهم. وإذا نظرنا إلى أهمية المعلم فن الجامعة و المدرسة، حيث يعتبر هو الذي يتنقل من

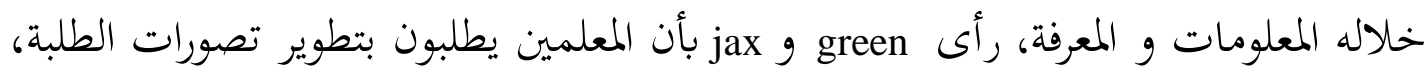
وتغيير وجهاهم و آراهم القديمة، وتعديل الأدوار تتعلق بالتحديات و و المشكلات، لأن تركيز التعليم ليس مجرد انتقال المعارف و المعلمومات من معلم إلى متعلم فحسب، ولمبه ولكن وجه8م و أرشدهم إلى التفكير الناقد والإبداعي(Green \& Jax, 2011) . التفكير الناقد حيث أشار به maiorana يهدف هذا التفكير الناقد إلى وصول إلى الفهم و التقييم من

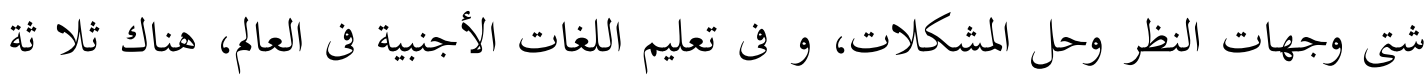

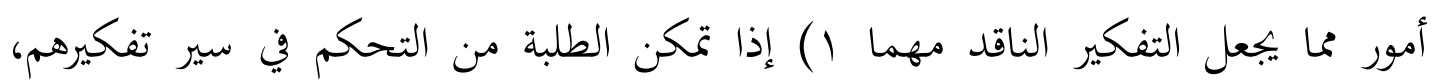

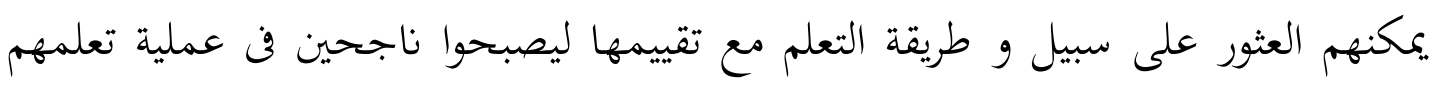

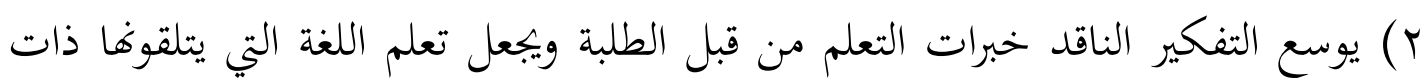

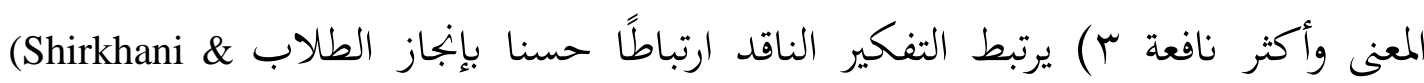
Fahim, 2011)، و تعلم اللغة الأجنيبة في المعظم يتماشى مع الأهداف حيث خطه الطلبة 
أو المعلمون من قبل التعلم، و بزيادة الوان أهداف منهاج التفكير الناقد ستصبح هذه العملية أكثر.

وأشار yudi في بحثه بأن ترقية الطلبة في التفكير الناقد يؤثر إلى ترقيتهم في فهم القرائى و القراءة ويؤكد Grabe بأن فهم القرائى في التعلم هو القدرة على فهم معلومات

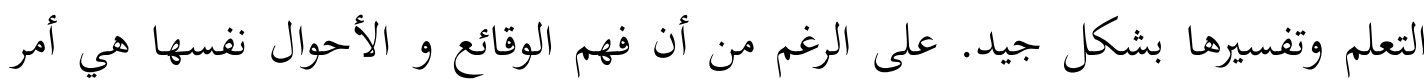

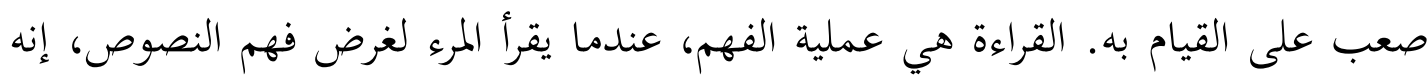

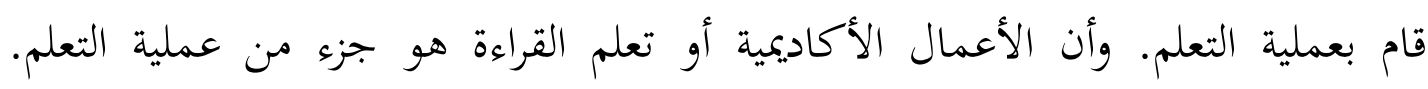

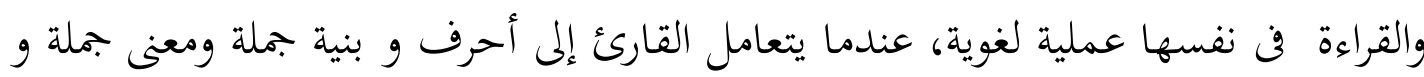

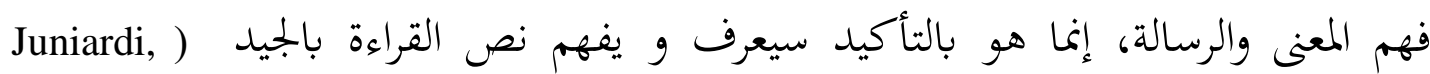
2018)• و وجود الزاد قببل عملية القراءة له تأثير كبير، خاصة فن المعرفة السابقة من القارئ. لأن كل قراءة ليس من السهل فهمها معنى و طرازا . القراءة هي أكثر من بجرد كلمات ما في الصفحة بل أهما الأمر التفكير \& Norris

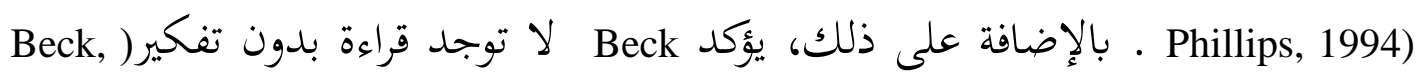

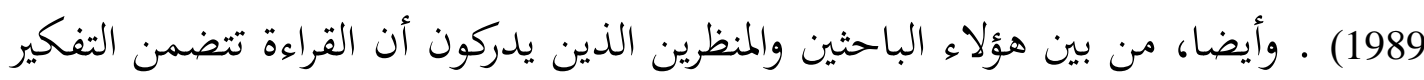

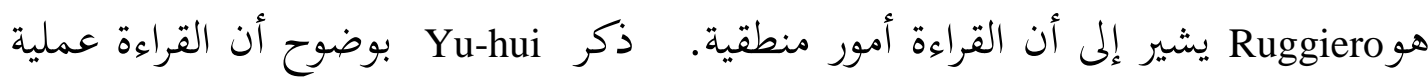

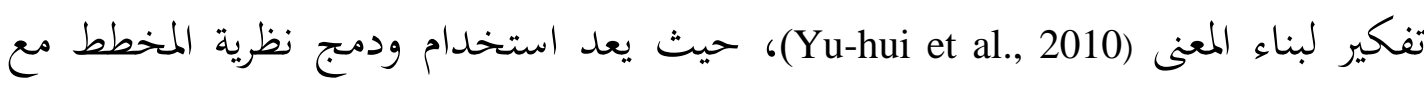
مبادئ التفكير الناقد واحدة من الطرق الفعالة لتعزيز مفهوم فهم القراءة و ذهب الآخر أغا عملية عقلية لتفسير الرموز (Khatam, 2019). شرح Norris أن التفكير الناقد يوفر وسيلة لشرح القدرة على صياغة نص غامض من خلال توليد تفسيرات بديلة، والنظر إليها في ضوء الخبرة والمعرفة العالمية، وتعليق القرار حتى تتوفر معلومات إضافية، وقبول التفسيرات البديلة(Norris \& Phillips, 1994) هذه العلاقة بين فهم القراءة و التفكير الناقد و المعرفة

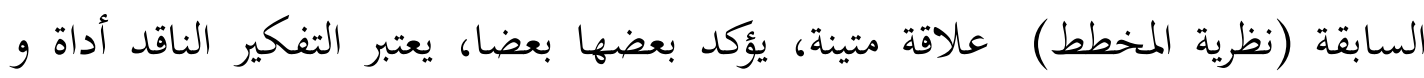

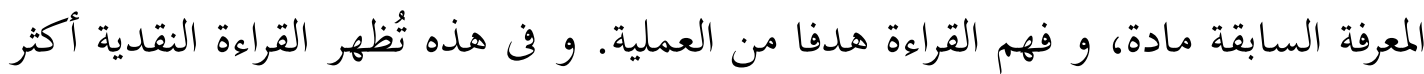


من مجرد القدرة على فهم المعنى الواضح ، فهي تتضمن التطبيق والتحليل والتقييم والخيال(Huijie, 2010). في الحوار السابق، تظهر بأن القراءة ليست عملًَ فيزيولوجيا فحسب، بل هي عمل عقلاني، وكيفية تأليف قراءة وفهمها ، بحيث يمكن معالجة الرسالة

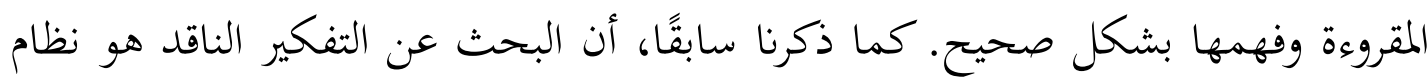
موجود في العقل لفتح معارف أعمق حول الكائن الذي تتم قراءته، مما يؤدي إلى نوعية جيدة من الفهم في القراءة.

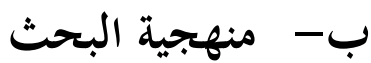

Research and (استخدم الباحث بحثا كيفيا وبكثا كميا بنوعه البحث والتطوير (Development وتجربة فعالة (Sugiyono, 2014). وقال Kleing Richey أن البحث والتطوير يقصد إلى اتيان

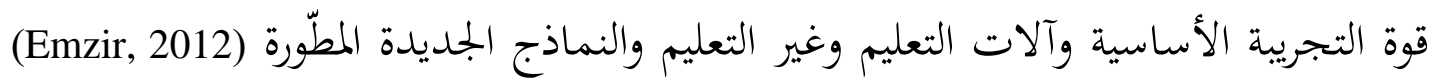

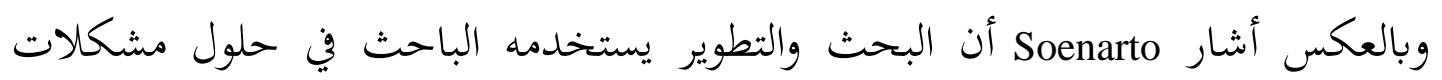
عملية التعليم والتعلم في الجو التربوى ومن خلاله أيضا يرقى فعالية عملية التعليم والتعلم في غرفة الدراسة. وأشار أن بينه وبين البحث التجربى فرق غير بعيد، أن الأول لا لتجربة التعبية النظري وأما الثانى لتجربة النظرى بخلاف Gall, Walter Borg أن في البحث والتطوير فيه التجربة لينظر الباحث فعالية الأشياء المطورة (Ainin, 2013). وفي الواقع أن معظم البحوث في عملية التعليم المتعلقة بالموضوع تركز كثيرا على بحث العلاقات وبتربة النظرى لا في انشاء

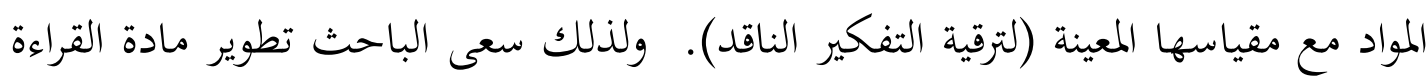
النطلقة من أساليب الحوار القرآنى لترقية التفكير الناقد حيث يعمل فيه تطويرى وتطبيق. استخدم الباحث نموذج التطوير بـ Bolly و Balitho وهي تتضمّن على النماذج الإجرائية

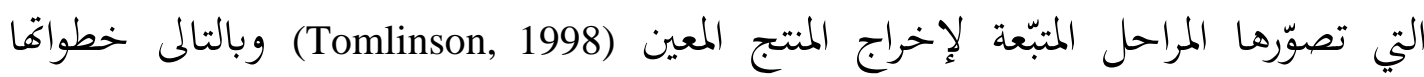
. (McGrath, 2002) 


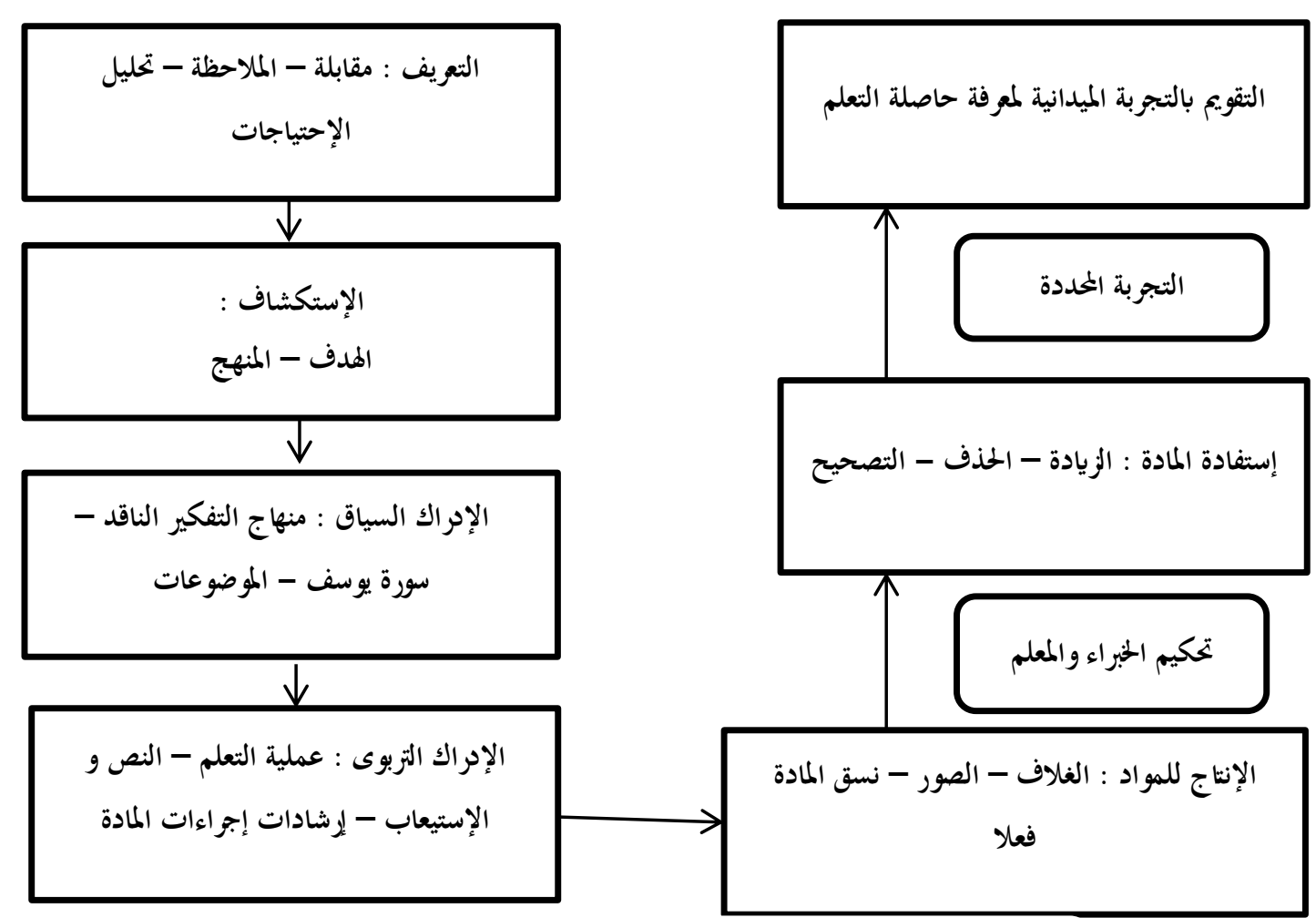

(McGrath, 2002) Balitho Jolly 1 ( : خطو ات

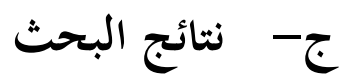

مرحلة التعريف (Identification)، في هذه المرحلة بدأ الباحث أن يقوم بالملاحظة والمقابلة ثم الإستبانة في الدراسة الميدانية الأولى، وجد الباحث من نتائج الملاحظة بعض معلموت عن عملية التعليم و التعلم في اللغة العربية، وأدوات التعليم وعملية التقييم، ثم في المقابلة حيث قام به الباحث مع معلم المادة، خبير للغة العربية في سمارندا، رئيس شبعة اللغة العربية في جامعة سمارندا الملكومية الإسلامية، والمساعد الثالث من لانشطة الطلبة قسم التعليم والتربية جامعة سمارندا الحكومية الإسلامية، وجد الباحث معلموت عن المشكلات حيث وجهها المعلم في غرفة الدراسة وأشار الإمميع مهمة تطوير المادة بالقرآن وترقية التفكير الناقد، من مميزات القرآن في المعنى و أهداف التفكير الناقد مناسبة للطلبة. 
في مرحلة الاستكشاف (Exploration) ، وجد الباحث أن المنهج الجامعى من جامعة سمارندا الحكومية الإسالامية تتكون من الرؤية والأهداف الرئيسية وهي (الرؤية) أن تصبح جامعة إسلامية متفوقة في تطور الحضارة الإسالامية وتتمثل هذه الرؤية إلى الأهداف الخمسة هي 1) تطوير العلوم والفنون والثقافة الإسلامية ذات الصلة بتنمية واحتياجات المجتمع r ) إنشاء الثقافة الأكاديمية قوية ومتجذرة r) تثقيف الطلبة على التفكير والنقد والإبداع والقدرة على تحقيق القيم الإسالامية في حياة المجتمع ع ) لينتج الخريجين ذا إيمان قوي واخلاق كريمة محترفين مثقفين 0) القيام بدور فعال في تنمية المجتمع من خلال التعليم والتدريس والبحث وخدمة المجتمع، ومن هذه المنطلقات أن تطوير المادة على ضوء القرآن للترقية التفكير الناقد مناسبة. مرحلة الإدراك السياقي (Contextual Realization) ، وجد الباحث أن معظم الطلبة يختارون سورة يوسف كمادة لمم في التطوير (نتائج الإستبانة). وفي ناحية التفكير الناقد هناك ركز الباحث إلى القابلية و المهارة كأهدافه في تطوير المادة خاصة في مجال التقويم. وبالتالى بعض الموضوع في المادة المطورة من سورة يوسف :

\begin{tabular}{|c|c|c|c|}
\hline الموضوع & المشهد & الموضوع & المشهد \\
\hline أصبح يوسف وزيرا & Ir & رؤيا يوسف & 1 \\
\hline لقاء يوسف مع إخوته & $1 r$ & المؤامرة & $r$ \\
\hline لقاء يوسف مع إخوته (r) & $1 \varepsilon$ & كيد الإخوة & $\mu$ \\
\hline عودة الإخوة & 10 & منزل عزيز مصر & $\varepsilon$ \\
\hline فقدان صواع الملك & 17 & الخلاص من التهمة & 0 \\
\hline قممة الإسترقاق & IV & 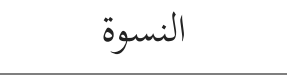 & 7 \\
\hline حزن و شوق يعقوب & 11 & ادخاله في السجن & V \\
\hline التعارف & 19 & يوسف في السجن & $\Lambda$ \\
\hline
\end{tabular}




\begin{tabular}{|c|c|c|c|}
\hline سماحة يوسف أخوته & $r$. & يوسف في السجن (r) & 9 \\
\hline الرجاء لن ينفد & TI & انفراج يوسف من المحنة & 1. \\
\hline البشارة واجتماع الشمل & Tr & انفراج يوسف من المحنة (r) & 11 \\
\hline
\end{tabular}

مرحلة الإدراك التربوي (Pedagogical Realisation)، في هذه المرحلة بدأ الباحث أن يعين الأنشطة المناسبة وكتابة التعليمات للاستخدام، مثل كيف عرض النص المقروء و أشكال الأسئلة و كيفة الإجراءات و بالتالى بعض ترتيب عرض النص في الموضوع الأول رؤيا يوسف:

\section{د-موضوع رؤيا يوسف}

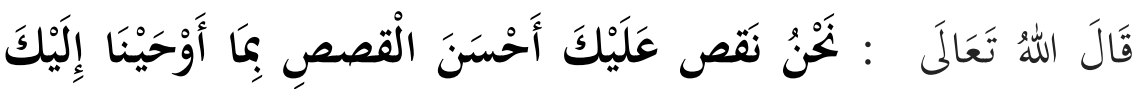

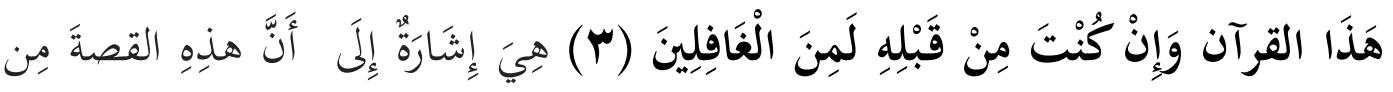

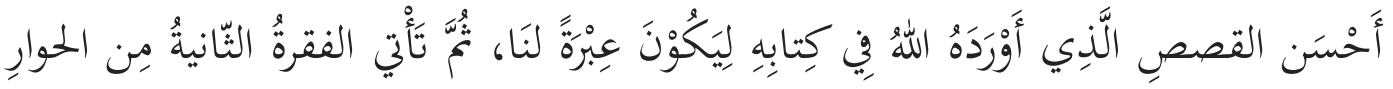

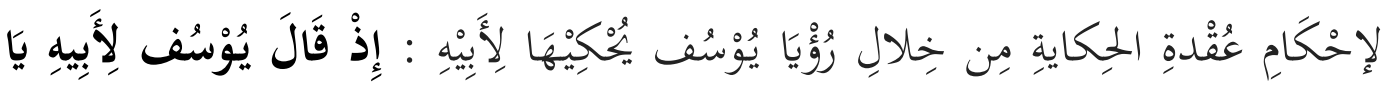

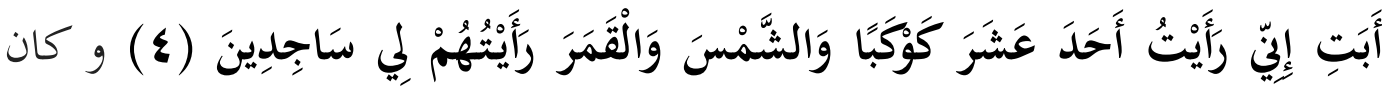

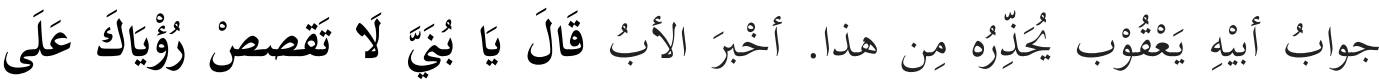

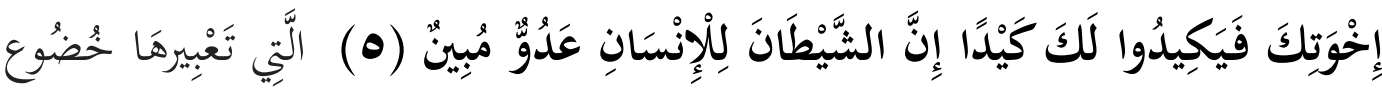

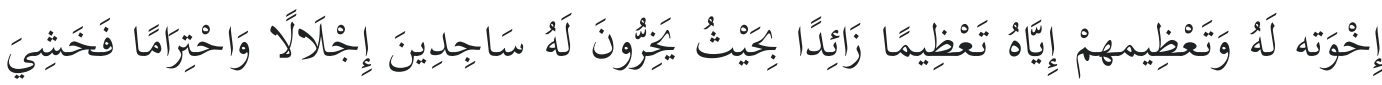

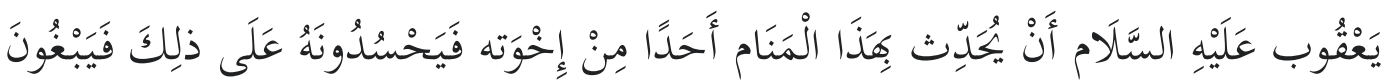

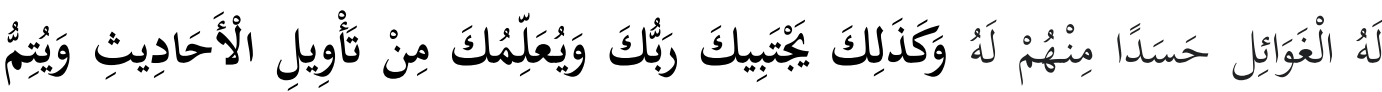

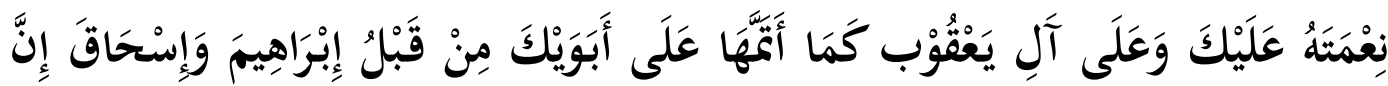

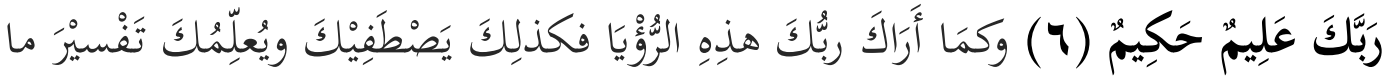

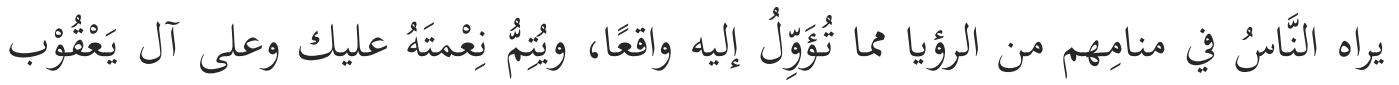


Edy Murdani Zulkifli, Wildana Wargadinata \& Sutaman

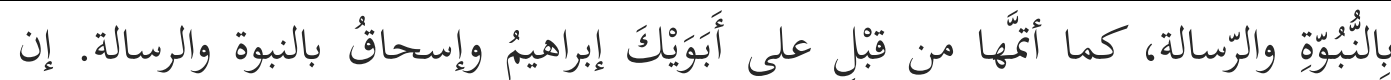

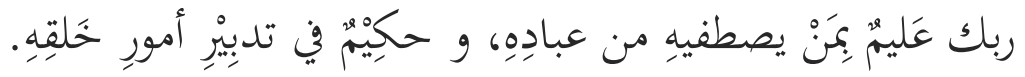
رسم ץ: مثال النص من الموضوع الأول

مرحلة الإنتاج للمواد (Physical Production). في هذه المرحلة ركز الباحث في عملية الإنتاج الطباعى مع مراعاة التخطيط والنوع والحجم والمرئيات والاستنساخ وطول الشريط وما إلى ذلك و بالتالى بعض الصور :
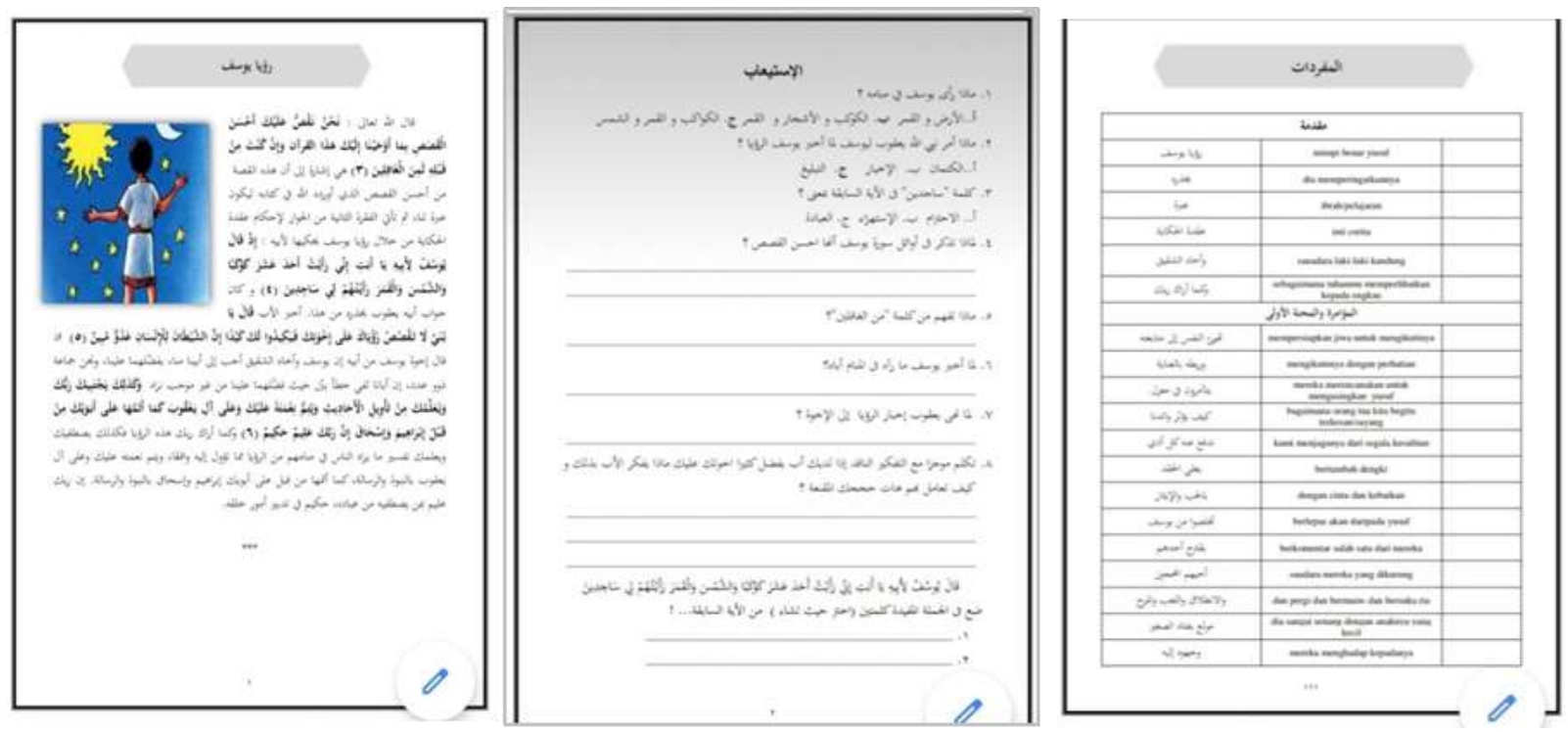

رسم بّ: صور النص، الاستيعاب و قائمة المفردات

في مرحلة إستفادة المنتج (Use) بتحكيم الخبراء والآراء من الطلبة في التجربة

المحددة. وبالتالى مرحلة التقويم من نتائج التجربية (Evaluation) 


\section{هـ - نتائج البحث ومناقشتها \\ 1 - مناقشة نتيجة البحث في المادة المطورة}

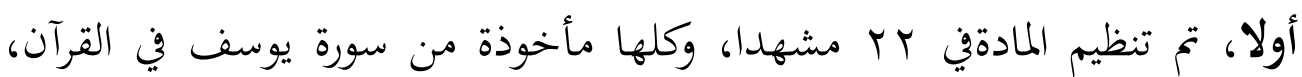
لكن كل موضوع يحتوي على مناقشة كافية لتدريب بعض مهارات التفكير لدى الطلاب، والتي يمكن رؤيتها من الأسئلة في كل موضوع، لكن هذه الموضوعات لا تزال مرتبطة

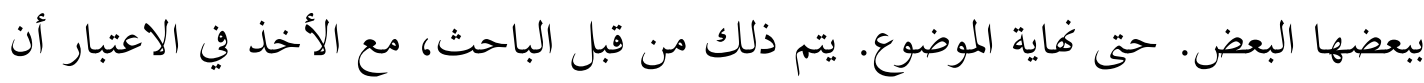

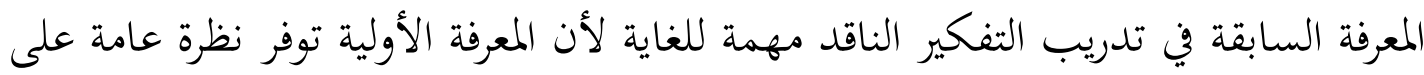
المعرفة السابقة (Juniardi, 2018).

ووجود هذه الموضوعات يدل على أن تغطية أهمية الإلمام بالمواضيع عامل مهم

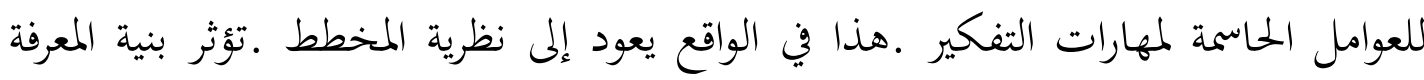

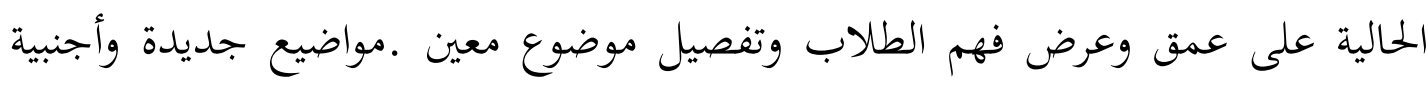
ركن الطلاب على ركود الأفكار كما يقبلها طالب واحد (Maru \& Matheos, 2019). ثانيًا، يبلغ عدد الصفحات التي استخدمها الباحث حوالي •م ورقة مكونة من بهن الغلاف، وكلمات مقدمة، ودليل لاستخدام المادة، ومعايير الكفاءة المطلوب تحقيقها، والمواد. وتتكون المادة التي قدمها الباحث من نص القراءة من الآيات والتفسير والإستيعاب ودماب حيث تتكون من الاختيار من متعدد وإجابات مكتوبة وتكوين جمل من كلمة القرآن تتعلق بالموضوع قيد الدراسة. في هذا الترتيب، يعني أن الباحث يستخدم ترتيب الوحدات في اتباع التسلسل (Purwanto dkk, 2007). من خلال نموذج ترتيب مثل هذا، يمكن للمعلمين والطلاب اتباع صورة لاتحاه

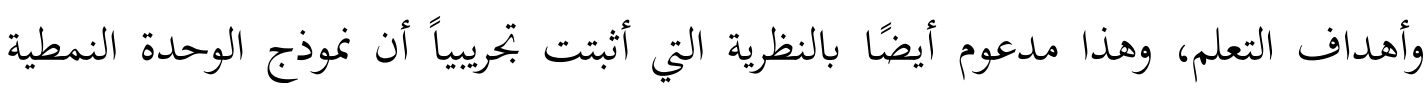

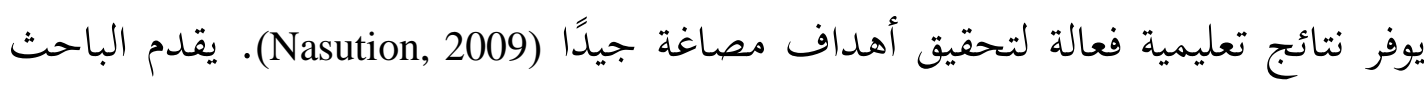

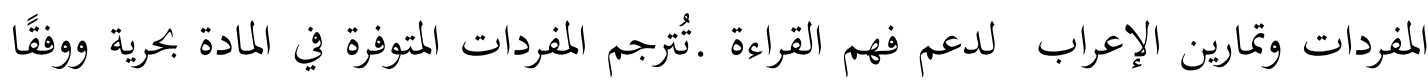

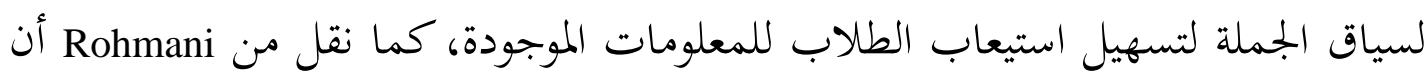


Edy Murdani Zulkifli, Wildana Wargadinata \& Sutaman

عمق التفكير الناقد لدى الطلاب يعتمد على إتقان اللغة (Indah, 2017). تعمل الكفاءة اللغوية كشرط يجب الوفاء به بكيث يمكن الوصول إلى المعرفة باعتبارها انعكاسًا للتفكير الناقد من قبل الطلاب الآخرين خاصة تعلم التفكير الناقد عبر اللغات، على الرغم من أنه في البحث الذي كتبه خالد، فإنه في فهم القراءة، فإن القواعد النحوية ليس لها تأثير كبير مقارنة بالمفردات (Khaldieh, 2001). ولكن الباحث لا يركز كثيرا في القواعد والإعراب في التعليم، وبالتالى بعض مضمون الموضوع : Y - مناقشة ميزات المادة المطورة المنطلقة من أساليب الحوار القرآنى أولاً، تتميز هذه القصة بأهفا من أحسن القصص وذلك قول الله تعالى" :شَنْ

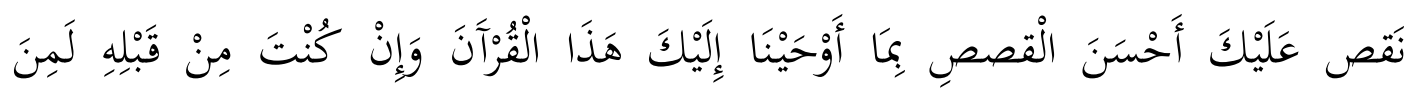
الْغَافِلينَ". وقد انفرد سورة يوسف بقصة يوسف ولم تشاركها فيها قصة أخرى، حيث أخذت أحداث القصة جميع السورة باستثاء الآيتين في أول السور وتسع آيات في آخرها. وقد تعدد الصور الاجتماعية في شتى المحاورات و هو بين الأب و الإبن : بُنَيَّ لَا تَقصصْ

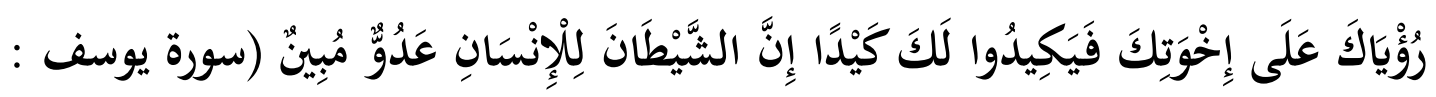

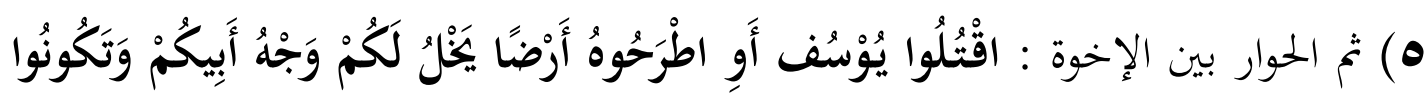
مِنْ بَعْدِهِ قَوْمًا صَالحِينَ (سورة يوسف : 9 ه) ثم الحوار عند قافلة التجار : وَجَاءَتَّ سَيَّارَةٌ

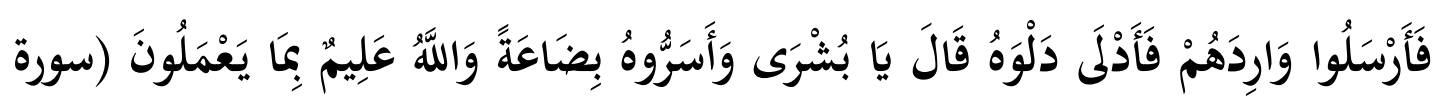

(19 : (19 )

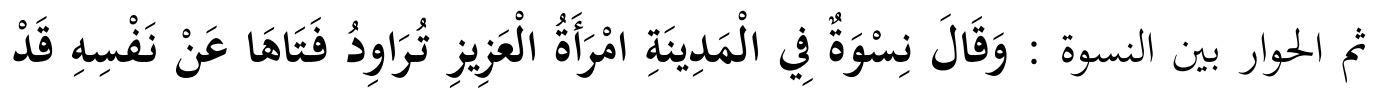

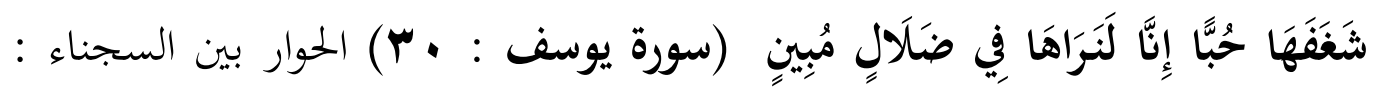

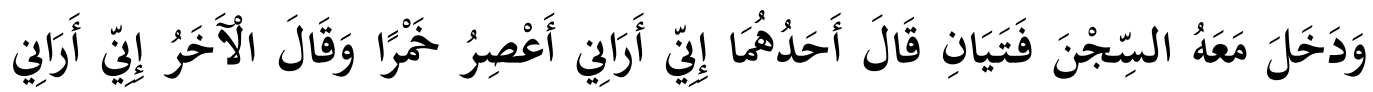

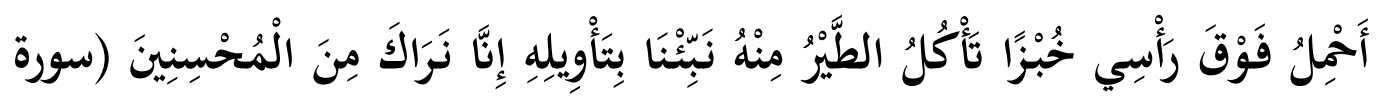

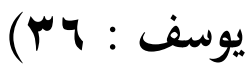


قام الباحث بتطوير هذه المادة التعليمية المستندة إلى القرآن من سورة يوسف

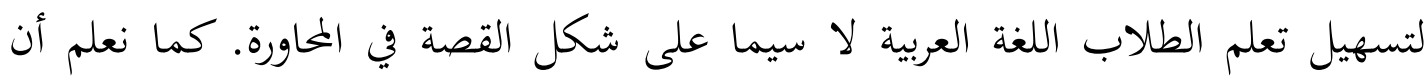
القرآن معجزة أنزلها الله على المسلمين، وفيه معجزة لغوية وتحدي للعرب حين ينافس جماله

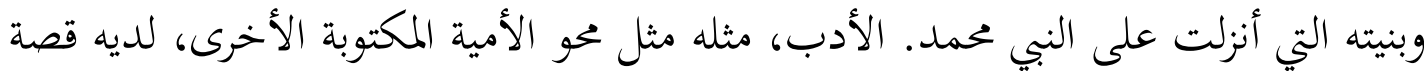
تقترح حدثًا لغويًا أساسيًا من وجهة نظر التعلم الماضي. في علم اللغة التطبيقي الحديث

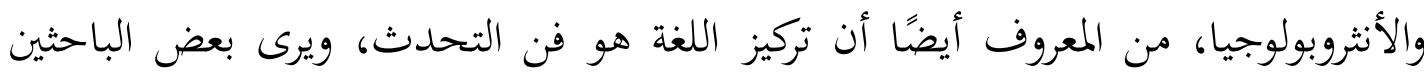

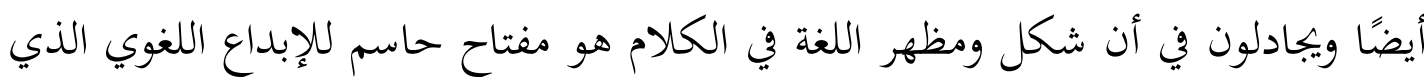
يتم إجراؤه في التفاعلات التي تتم كل يوم (Zaid, 2011). لذلك تحدى الله العرب الذين

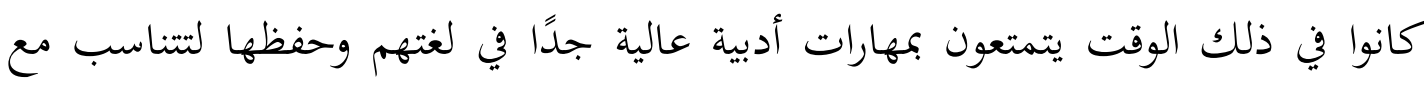

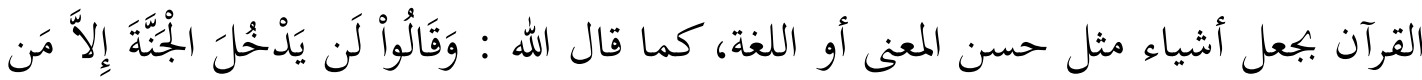

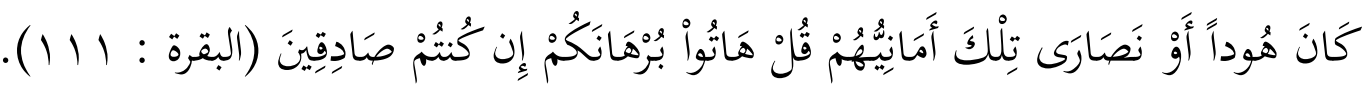
ثانيا، في هذه العلاقة، مع المواد التعليمية على ضوء أساليب الحوار القرآنى، فهي تساهم في تعلم اللغة العربية من الشباب المسلم من الطلاب من يتلقى العربية، وكذلك فهم سياق اللغة العربية في القرآن. كما نعلم جميعًا، أن القرآن يحتوي على كلام الله وكمرشد

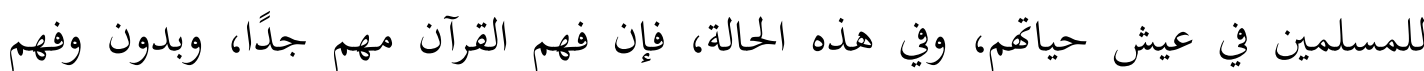

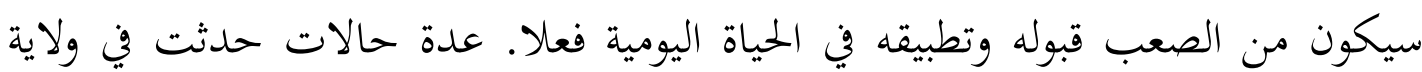
ماليزيا، معظم حفاظ القرآن لا يفهمون معنى القرآن بشكل صحيح ( Saadah \& .(Baharuddin, Nurfarhana, 2017 ثالثا، يتم تطوير هذه المادة التعليمية على ضوء أساليب الحوار القرآنى، حيث يتم تقديم قصة وفقًا للسياق الحالي. تُعد هذه المحاورات في نظام التعلم مهمة لصقل مهارات

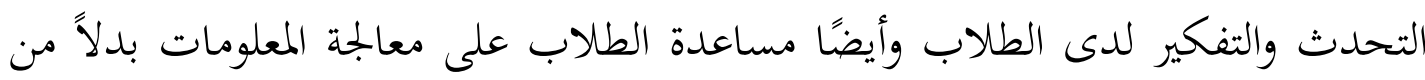
ججرد تلقيها، حيث يتمرن الطلاب على التفكير في المادة التي تتم مناقشتها و هذا تتماشى مع قول (Dahari, 2019) بأن الطلبة لابد من أن يحلل الآراء هل هي مناسب بالمقال أو 
الحال مع المعايير التى تم اتفاقها قبل أن يستنبط. ومن ناحية أخرى، فإن المواد التعليمية في

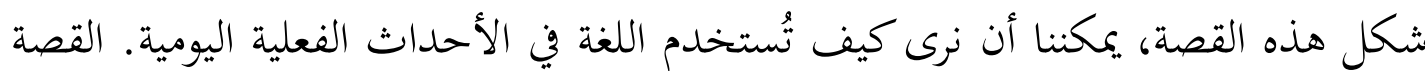

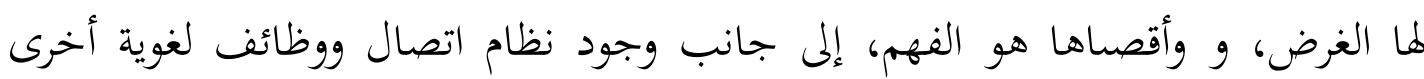
مرئية. من خلال القصة، يعرف المتعلم كيف يمارس القراءة الناقدة لفهم قراءة القصة

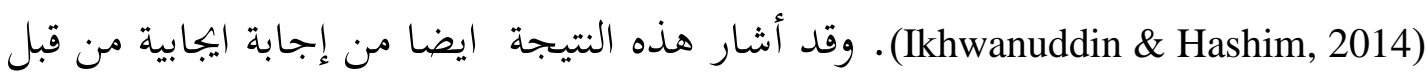
الطلبة بعد تطبيق المادة (Neilsen, 1989). في المحاورات التي تحدث في المواد التعليمية المطورة

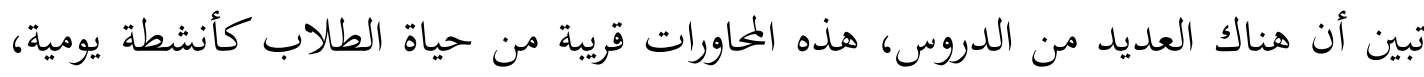

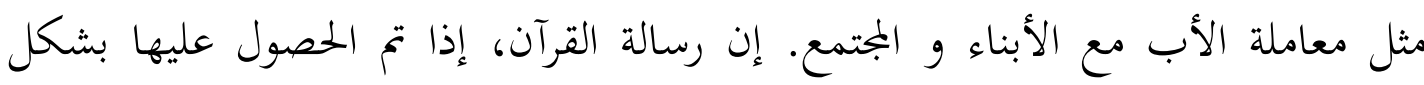

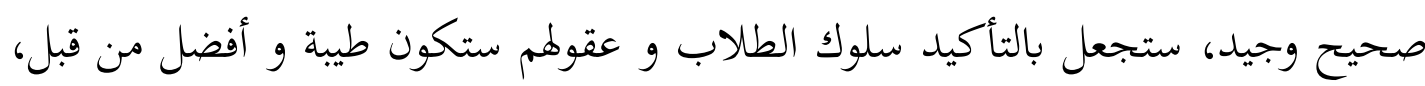
بالإضافة إلى ذلك، إذا كان الاعتقاد قائمًا على فهم جيد بعد المرور بعملية التفكير النقدي ، فلن يتزعزع الاعتقاد بسهولة عند مواجهة صعوبات أو في حالة حرجة(Zhaffar, 2017).

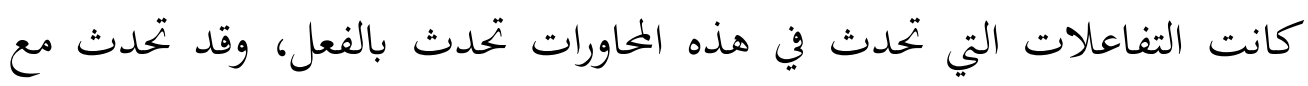

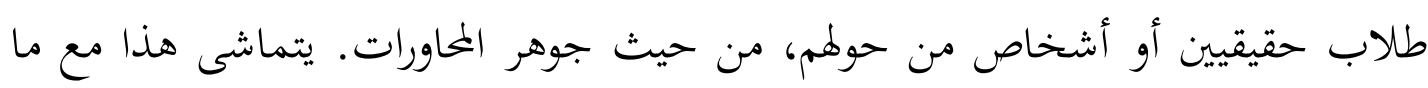

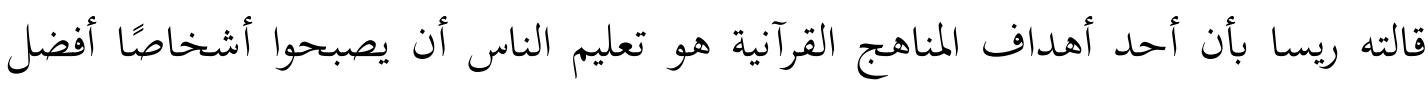

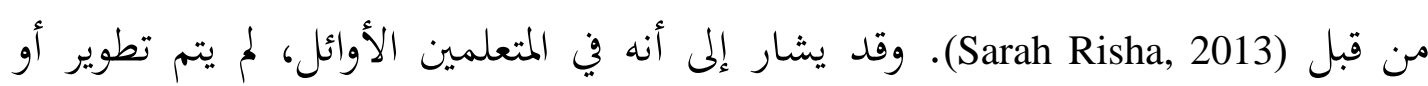
ممارسة استراتيجيات التفكير الناقد على نطاق واسع خلال التعليم الابتدائي والثانوي . لذلك، يلتزم المعلم بمساعدة الطلاب على تطوير المهارات اللازمة لتجميع الفروق الدقيقة

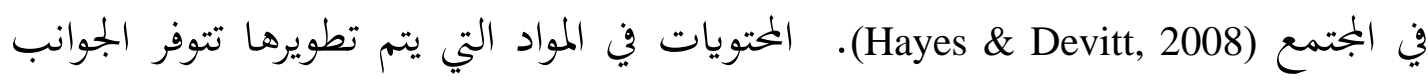
التي تؤدي إلى ترقية مهارات التفكير الناقد، بحيث يكون دور المعلم هو التوجيه فحسب لتونب

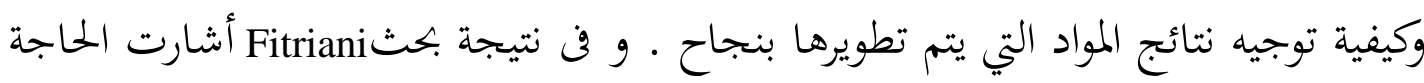
إلى مواد تعليمية داعمة محددة كإرشادات تعليمية منظمة ومفصلة لتعليم الأثاث لمهارات التفكير الناقد والتحليل الناقد للطلاب بحيث تكون أهداف التنمية عالية بيمكن تحقيق هذا 
التفكير الناقد في التعلم و التعليم (Fitriani \& Asy’ari, 2019). في هذه المادة المطورة زعم الباحث ستكون بعض هذه الأثاث المدعمة في ترقية التفكير الناقد المنطلقة من أساليب الحوار القرآنى و بالتالى مثال منهاج التفكير الناقد في المادة المطورة.

r- مناقشة نتائج البحث في المادة المطورة و تأثيرها على ترقية التفكير الناقد لدى الطلبة

تحتوى هذه المادة المطورة على سورة يوسف وشرح لآيات المحاورات الواردة. فيها

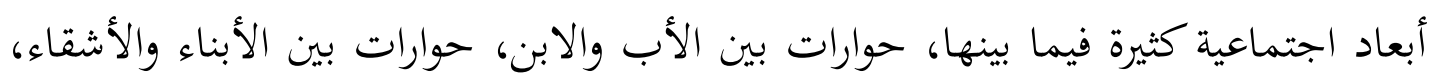

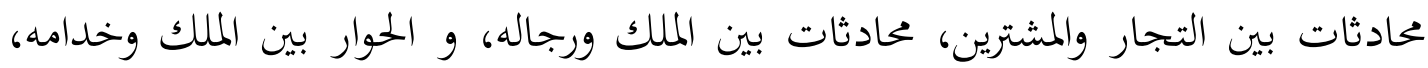

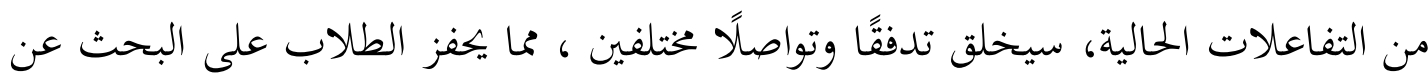

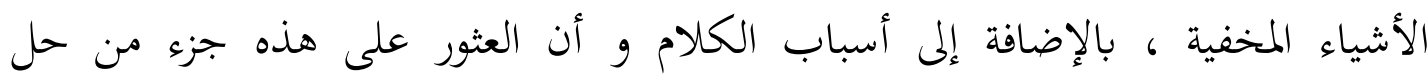
المشكلات الذي يجب صقله في عملية التعلم من أجل تعزيز الموقف العلمي بحاهـم(Pusparatri, 2012). لقد جعل المجتمع علاقاهم مع الغير تتم بإستخدام لغوى،

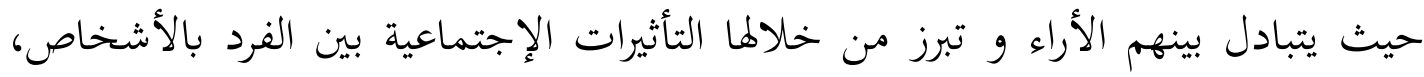
بين فئة و فئة أخرى و مهنة إلى مهنة أخرى. و هذه الحالة من ظواهر إجتماعية تورهي تولدت سمات خاصة للكلام حيث اتفقو شتى المجتمع على حد سواء في مهموم التكلم بينهم (Agha, 2007). في المواد التعليمية التي طورها الباحث، تم تقسيمها إلى عدة آثار لترقية مهارات التفكير الناقد، الأول هو القابلة الذي يتكون من الدقة و البحث عن المعلومات

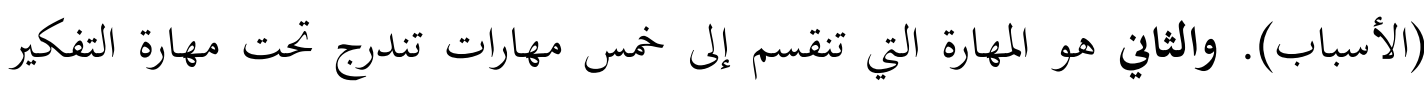
الناقد، وهي القدرة على التمييز بين الحقائق والآراء، التمييز بين الحجج الصحيحة وغير

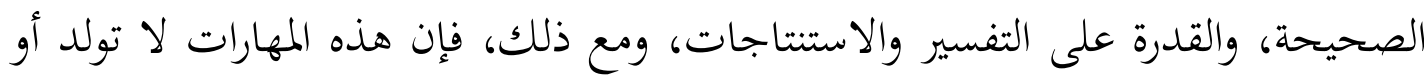

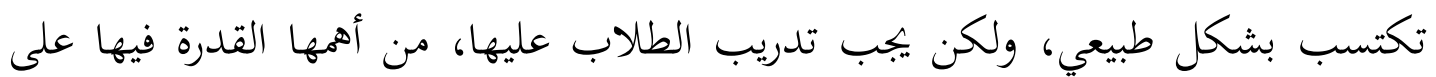


Edy Murdani Zulkifli, Wildana Wargadinata \& Sutaman

تفسير المشكلة التي تتم دراستها (Changwong et al., 2018) . فيما يلي تداعيات المواد التعليمية على مهارات التفكير الناقد من حيث القابلية والمهارات.

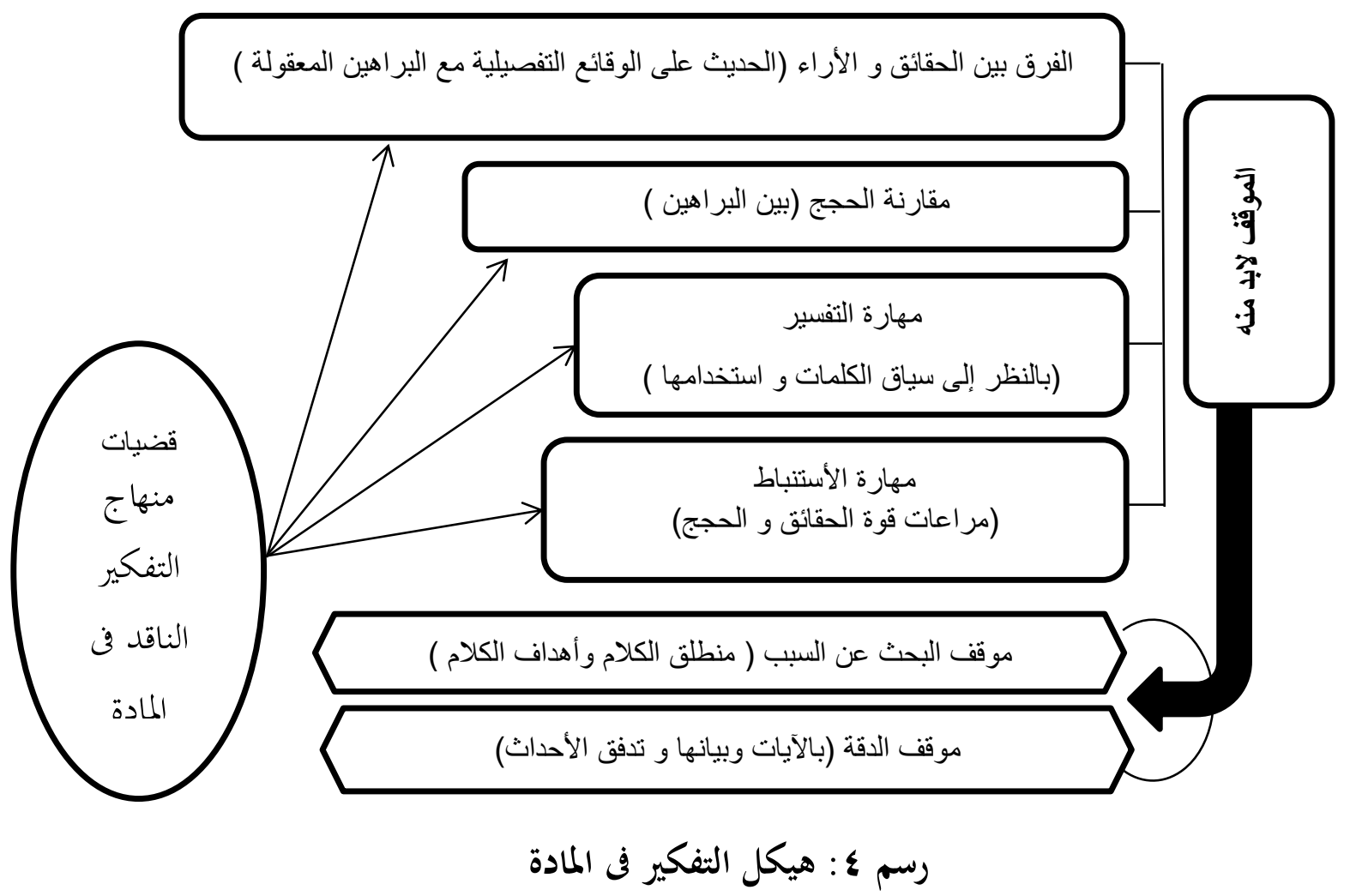

ع - مناقشة نتيجة البحث في فعالية استخدام المادة المطورة. بناءً على نتائج اختبار t و حساب N GAIN، تبين وجود فروق في نتائج تقييمات الطلاب قبل وبعد إعطائهم تعليم القراءة باستخدام المواد المطورة على ضوء أساليب الحوار القرآن في ترقية مهارة التفكير الناقد. كانت هناك زيادة في قيمة التقييم، ولكن في تحليل فعالية استخدام المواد التعليمية، تم تصنيفها على أهما فعالة للغاية. أكمل الطالاب السابقون مناقشتين أساسيتين تتعلقان بالقراءة المعاصرة. هذا يجعل الطلاب لديهم معرفة مسبقة (المعرفة السابقة) المتعلقة بإتقان تقنيات القراءة ويساهم في قدرة الطلاب الأولية في القراءة الناقدة. يتماشى هذا مع العبارة القائلة بأنه من المهم في القراءة الناقدة أن 
يكون لديك معرفة مسبقة يمكن أن تساعد المعرفة السابقة الطلاب في التعلم أو تعوقهم، اعتمادًا على طبيعة المعرفة السابقة. بل في كل درس، ينصح المعلم الطلاب دائمًا بقراءة

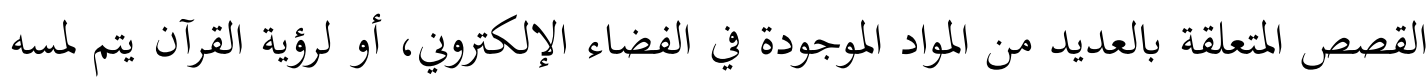

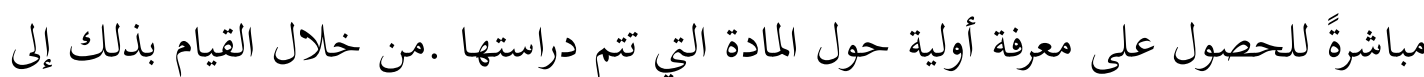
حد ما يساهم في الفهم عند دراسة المادة المعنية .يتم ذلك من قبل الباحث يعتبر أن المعرفة

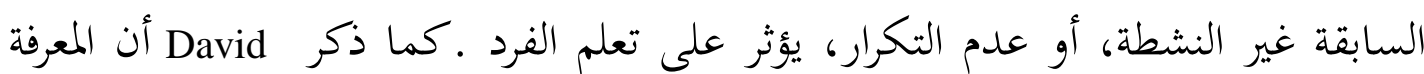

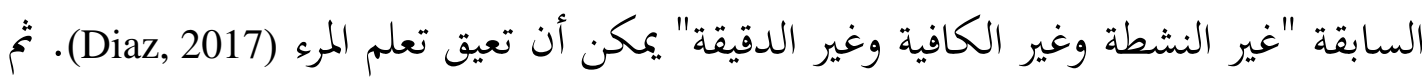
بالنسبة نتائج هذه لم تكن مرتفعة، لان المادة على الشكل اللكترونى أي لان تعليم تم انجازه من خلال جاهز zoom فمسيره لا كما في غرفة الدراسة حيث إلقاء المادة و شرحها و

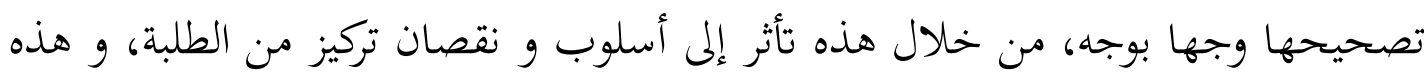
تعليقات تأتى من قبل الطلبة بعد تجربة المادة من نتائج الإستبانة. و هذه تتماشى مع ما قالته Niken في بحثها أن تغير المعلم في أسلوب التعليم في حالة الوباء يأثر على تركيز الطلبة

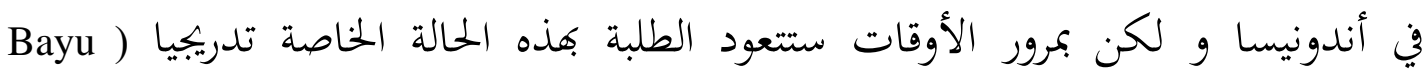
.(Argaheni, 2020

\section{و - الحخلاصة}

الأمور الجديدة في هذه الدراسة هي المواد التعليمية التي تحتوي على الحقائق والآراء

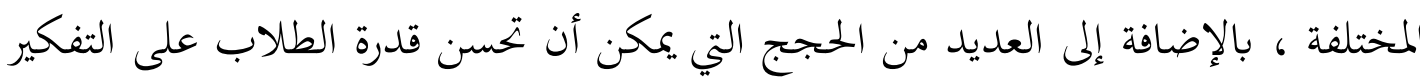

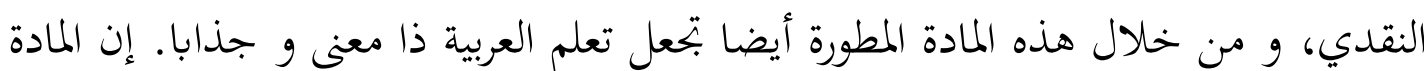
المطورة تتركز من سورة واحدة و تضم فيها القصة و العبرة ( الأساليب التربوية )، و تعلم اللغة العربية لترقية التفكير الناقد لدى الطلبة فن نفس الوقت ليس من أمر سهل، و لذهلك لابد من الجهود من قبل المعلم. 


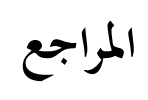

Abdul halim hifni. (1995). Uslub al-muhâwarah fil al-qurân al-Karim. al-Hay'atul misriah al-Ammah lil kitâb.

Agha, A. (2007). Language and sosial relations. cambride university press.

Aini, A., \& Ramli. (2018). Critical Thinking From Stem Education And Al-Quran Perspectives. Journal of Engineering Science and Technology Special Issue on I-CITE 2018, 35-41.

Ainin, M. (2013). Penelitian Pengembangan. Jurnal OKARA, I/(Tahun 8), 96-110.

Akhavanmalayeri, S. M., \& Faghihi. (2018). Designing and Validating Critical Thinking Curriculum for the Undergraduate Course Based on Stories and Parables of the Holy Quran. Journal of Quran and Medicine, 3(3), 115-125.

Arifin, S. (2020). The Role of Critical Reading to Promote Students' Critical Thinking and Reading Comprehension. JURNAL PENDIDIKAN DAN PENGAJARAN, 53(3), 318-327. https://dx.doi.org/10.23887/jpp.v53i1.

As sayyid muhammad husain fadhlullah. (1396). Al hiwâr fil qurân - qowai'duhu asâlibuhu - mu'thiyatuhu. dar al-Malâk.

Bayu Argaheni, N. (2020). Sistematik Review: Dampak Perkuliahan Daring Saat Pandemi Covid-19 Terhadap Mahasiswa Indonesia. Placentum Jurnal Ilmiah Kesehatan Dan Aplikasinya, Vol.8(2), 100-108.

Beck. (1989). The Reading Teacher. International Literacy Association, Vol. 42, No. $9,676-682$.

Changwong, K., Sukkamart, A., \& Sisan, B. (2018). Critical thinking skill development: Analysis of a new learning management model for Thai high schools. Journal of International Studies, 11(2), 37-48. https://doi.org/10.14254/2071-8330.2018/11-2/3

Dahari. (2019). Implementation critical thinking in Teaching Islamic Education. (International Journal of Academic Research in Progressive Education Development, 8((4)), 805-823.

Diaz, K. V. L. T. (2017). Prior Knowledge: Its Role in Learning. https://doi.org/10.13140/RG.2.2.26816.69125

Emzir. (2012). Metodelogi penelitian dan pendidikan: Kuantitatif dan Kualitatif. Rajawali press.

Fitriani, \& Asy'ari. (2019). Exploring the Prospective Teachers' Critical Thinking and Critical Analysis Skills. Jurnal Pendidikan IPA Indonesia, 8((3)), 379-390. https://doi.org/10.15294/jpii.v8i3.19434

Green, K., \& Jax, C. (2011). Problem solvers are better leaders: Facilitating critical thinking among educators through online education. Procedia - Social and Behavioral Sciences, 15, 727-730. https://doi.org/10.1016/j.sbspro.2011.03.173 
Hayes, K. D., \& Devitt, A. A. (2008). Classroom Discussions with Student-Led Feedback: A Useful Activity to Enhance Development of Critical Thinking Skills. Journal of Food Science Education, 7(4), 65-68.

Huijie, L. (2010). Developing a hierarchical framework of critical reading proficiency. Chinese Journal of Applied Linguistics, 33, 40-54.

Ikhwanuddin, M., \& Hashim, C. N. (2014). Relationship between Memorization Technique, Mastery of the Arabic Language and Understanding of the Qur'an. IIUM Journal of Educational Studies, 2(2), 84-97. https://doi.org/10.31436/ijes.v2i2.46

Indah. (2017). Critical Thinking, Writing Performance and Topic Familiarity of Indonesian EFL Learners. Journal of Language Teaching and Research, Vol. 8(No. 2), 229-236. https://doi.org/10.17507/jltr.0802.04

Juniardi, Y. (2018). Students' Critical Thinking And Their Reading Comprehension Ability. Center for Studies on Language and Culture - Atma Jaya Catholic University of Indonesia, 10.

Khaldieh, S. (2001). The Relationship between Knowledge of I'raab, Lexical Knowledge, and Reading Comprehension of Nonnative Readers of Arabic. The Modern Language Journal.

Khatam, A. (2019). Ritical Thinking Skills, Critical Reading and Foreign Language Reading Anxiety in Iran Context. International Journal of Instruction, 12(3), 219-238.

Laleh Bakhtiar. (2017). Critical Thinking and the Choronological Quran in the Life of Prophet Muhammad. Kazi Publication.

Maru, M. G., \& Matheos, D. (2019). Performing Critical Thinking: Evidence from Students' Stories. ICESSHum, 335, 906-911. https://doi.org/10.2991/icesshum-19.2019.141

McGrath. (2002). Materials evaluation and dsign for language teaching. edinburgh university press.

Nasution. (2009). Berbagai pendekatan dalam proses belajar dan mengajar. Jakarta, Bumi aksara.

Neilsen, A. R. (1989). Critical thinking and reading, empowering learners to think and act. ERIC Clearinghouse on Reading and Communication Skills.

Norris, S. P., \& Phillips, L. M. (1994). The Relevance of a Reader's Knowledge within a Perspectival View of Reading. Journal of Reading Behavior, 26(4), 391-412. https://doi.org/10.1080/10862969409547860

Purwanto dkk. (2007). Pengembangan modul. Depdiknas.

Pusparatri, R. K. D. (2012). Strategi Pembelajaran Berbasis Masalah Untuk Meningkatkan Kemampuan Berpikir Kritis Siswa. Jurnal Ilmiah Guru Caraka Olah Pikir Edukatif, 16(2), Article 2. https://journal.uny.ac.id/index.php/cope/article/view/3961

Qadhlawi, Y. (2016). Wajibuna nahwal Quran. 
Edy Murdani Zulkifli, Wildana Wargadinata \& Sutaman

Rezaei, S., Derakhshan, A., \& Bagherkazemi, M. (2011). Critical Thinking in Language Education. Journal of Language Teaching and Research, 2(4), 769777. https://doi.org/10.4304/jltr.2.4.769-777

Saadah, A. R., \& Baharuddin, Nurfarhana. (2017). Exploring the Level of Understanding the Content of Quran among Diverse Groups of People. Journal Sains Insani, Vol.2(No.1), 61-65.

Sarah Risha. (2013). Education and Curricular Perspectives in the Quran. ARIZONA STATE UNIVERSITY.

Shirkhani, S., \& Fahim, M. (2011). Enhancing critical thinking in foreign language learners. 6.

Sugiyono. (2014). Metode Penelitian Kuantitatif kualitatif dan $R \&$ D. Alfabeta.

Sulton bin musfir as-Shoidi. (1431). Daurul hiwar fi ta'zizi al-amni al-Fikri. min wizâroti at-tarbiyah wa at-ta'lim al-Idariyah al-Ammah li at-Tarbiyah wa atTa'lim.

Tomlinson. (1998). Material Development In Language Teaching. Cambridge University Press.

Yu-hui, L., Li-rong, Z., \& Yue, N. (2010). Application of Schema Theory in Teaching College English Reading. 7.

Zaid, M. A. (2011). Language Acquisition, Linguistic Creativity and Achievement: Insights from the Qur'an. Jurnal Kemanusiaan, Vol. 18, No. 2, 75-100.

Zhaffar. (2017). Elemen pemikiran kritis dalam konteks kemahiran berfikir aras tinggi. ASEAN Comparative Education Research Journal on Islam and Civilization (ACER-J)., 1(2), 92-101. 